\title{
Düzenli Bir Betonarme Binada Düşey Deprem Bileşeninin Yapısal Davranışa Etkisi
}

\author{
Müberra Eser AYDEMİR ${ }^{1}$, Serik JAKAYEV²
}

\begin{abstract}
Özet
"Düzenli bir betonarme binada düșey deprem bileșeninin yapısal davranışa etkisi" - olarak adlandırılan araştırmada depremin düşey bileșeninin yapısal davranışa etkisini tespit etme doğrultusunda çalışma yapılmıştır. Çalışmada öncelikli olarak bina türü olarak 5 katlı betonarme bina belirlenerek, yapı elemanlarının ön boyutlandırması yapıldıktan sonra ülkemizde mühendislik tasarım alanında sık kullanılan "Sta4CAD" mühendislik tasarım programı yardımıyla yapı elemanlarının donatı hesabı yapılmıştır. Bilgisayar ortamında hazırlanmış modele depremin etkisini uygulamak için yedi tane deprem kaydı seçilmiştir. "Seismostruct" doğrusal olmayan çerçevelerin statik ve dinamik çözüm ve analiz programıyla deprem kayıtları yatay ve yatay artı düşey olarak modele tek tek uygulanmıștır. Analiz sonrasında yatay ve yatay artı düșey deprem kayıtları etkisinden yapıda oluşan normal kuvveti, kesme kuvveti karşılaştırılmıştır. Elde edilmiş veriler ışığında, depremin düşey bileşeninin özellikle kolonlardaki eksenel kuvvetlerin artışına sebep olunduğu görülmüştür. Kolon kesme kuvvetlerinde depremin düşey bileşeninin eklenmesiyle önemli miktarda artışlar gözlenmese de yaklaşık yüzde 10 oranında artış kaydedilmiştir. Kat ötelemelerinde ve toplam yapısal deplasmanda ise belirgin değişiklikler kayıt edilmemiştir.
\end{abstract}

Anahtar Kelimeler: Deprem Mühendisliği, Depremin Düşey Bileșeni, Normal Kuvvet, Kesme Kuvvet

\section{Effect of The Vertical Earthquake Component on Structural Behavior of A Regular Reinforced Concrete Building}

\begin{abstract}
After some observations of design practices worldwide, it is generally considered horizontal components of earthquakes are more destructive than vertical components. Because of this fact, it's vertical components of earthquakes are sometimes neglected. On the other hand; some recent observations have revealed that the vertical components of earthquake can have more destructive effects on buildings. In this analytical study, investigations were conducted to evaluate effects of vertical components of earthquake on structural behavior of buildings. Firstly, type of the building was determined, and preliminary calculations of structural elements were made, and the calculation of reinforcement of structural elements was made by the computer program Sta4CAD. Seven earthquake records were selected and their effects applied to the computer models prepared.
\end{abstract}

\footnotetext{
1 Doç. Dr., İnșaat Mühendisliği Bölümü, İstanbul Aydın Üniversitesi, İstanbul

2 İnşaat Mühendisi, Senimdi Kurylys LLP (Bechtel \& Enka joint venture), Atyrau/Kazakhstan

İlgili yazar / Corresponding author: serikjakayev@gmail.com
}

Bu makaleye atıf yapmak için- To cite this article Aydemir M. E. ve Jakayev, S. (2019). Düzenli Bir Betonarme Binada Düşey Deprem Bileșeninin Yapısal Davranışa Etkisi. Afet ve Risk Dergisi, 2(1), 1-13. 
Düzenli Bir Betonarme Binada Düșey Deprem Bileșeninin Yapısal Davranıșa Etkisi

With the help of program "Seismostruct" horizontal, horizontal plus vertical forces of earthquake records were applied to these models. Results analyses, from exposure of horizontal, and horizontal plus vertical earthquake forces were compared, values of normal forces, shear forces of the structure were examind and it was found that the horizontal plus vertical components influenced the building axial forces on columns, especially in the middle columns. Although, shear forces did not show a significant increase on columns, the difference in one of seven earthquake records was ten percent. No changes were recorded in shear forces on structural beams. No significant changes have been found in displacement and story drifts too.

Keywords: Earthquake Engineering, Vertical Component, Horizontal Component, Axial Force, Shear Force

\section{GİRIŞ}

Dünya genelinde depremin etkisi olarak yatay deprem etkisinin daha çok etkili olduğu gözlemlenerek kabul olunduğu için depremin düşey etkisine çok fazla değer verilmemiştir. Bazı deprem sonuçlarında depremlerin düşey bileşenleri yatay bileşenleri kadar, belki de daha şiddetli davranabilirler. Bununla birlikte, günümüzde düşey deprem hareketlerinin özellikleri ve yapıya etkisi mekanizmaları yeterli anlaşılmamıştır. Düşey zemin hareketinin oluşmasına neden olan $\mathrm{P}$ dalgaları özellikleri, yatay yer sarsıntısını meydana getiren $\mathrm{S}$ dalgalarından daha farklıdır. $\mathrm{P}$ dalgalarının dalga boyu $\mathrm{S}$ dalgalarından çok daha kısadır, o yüzden de dikey sarsıntı daha yüksek frekans içeriğine sahiptir (Kim SJ, Holub CJ, Elnashai AS., 2011). Yüksek sismik bölgelerin, özellikle fay hatlarına yakın alanların güçlü dikey sarsıntı yaşama potansiyeli olduğu düşünülmektedir (Bozorgnia Y, Niazi M, Campbell K., 1995). Geçmişimizde depremin düşey bileşenine yeterli önem verilmediğinden deprem sırasında yapıda beklenmedik hasarlar oluşmuştur. Çalışma konusu depremin düşey bileşenleri hakkında olup, analitik çalışma o doğrultuda gelişecektir.

1958 senesinde amerikan sismologu Richter: “Çalışılan hipotezden ziyade, sabitlenmiş, gerçek olarak daha az kabul edilmesi gereken kanıtlar vardır; herhangi başka yerlerden merkez üssü çevresinde, depremin dikey hareket bileșeni, yatay bileşenlere göre daha büyüktür" - ifadesinde bulunmuştur (Y. Bozorgnia, 2014).

Depremin düşey bileşenini daha iyi anlamak için son zamanlarda da çalışmalar devam etmekte olup ilk çalışmalar Chopra (1966); Newmark vd. (1973); Weichert, Wetmiller ve Munro (1986); Abrahamson ve Litehiser (1989); Bozorgnia, Niazi ve Campbell (1995); Papazoglou ve Elnashai (1996); Ambraseys ve Douglas (2003)'dır. Bu çalışmalarda araştırmacılar düşey etkisi şiddetli Northridge, Kobe, Kocaeli ve daha başka deprem kayıtları üzerinde çalışmışlardır.

“Düșey Deprem Hasar Etkisinin Analitik ve Saha Gözleminin Kanıtları” adlı çalıșmalarında Papazoglou ve Elnashai (1996) üç tane deprem: a) Kalamata-Yunanistan depremi, 13 Eylül, 1986; b) Northridge depremi, 17 Ocak, 1994; c) Kobe, 17 Ocak, 1995 tarihlerindeki depremlerin binalara verdikleri hasarları incelemişlerdir. Bahsedilmiş üç tane depremin de V/H oranı dünyaca kabul görülen 2/3 değerlerini geçmişlerdir. Araştırmacılar saha gözlemleri sonucu olarak, deprem sırasında binaların hasar görmesi sadace kesme veya eğilme kapasitesini aşmasından değil, depremin dikey etkisinden meydana gelen aşırı eksenel gerilmelerden de olabileceğini kanıtlamışlar (Farsangi ve Tasmini, 2016). Papazoglou ve Elnashai (1996) çalışmalarının analitik kısmında çelik çerçeveli binalarda depremin düşey etkisinin eksenel kuvvete katkısını hesaplamada Papaleontiou ve Rosset (1993) verilerini, betonarme binalarda ise Koukleri (1992) verilerini kullanmışlar. Kullanılan verilere göre binanın eksenel kuvvetlerinin artmasında depremin düşey etkisinin katkısı çok olduğu gözlemlenmiştir.

Kim ve Elnashai (2008) çalışmalarında analitik ve deneysel araştırmalar sonucunda betonarme yapılar sadece yatay deprem etkisine maruz kaldığından daha çok birleşik hareketten: yatay ve 
Afet ve Risk Dergisi Cilt: 2 Sayı: 1, 2019 (1-13)

Müberra Eser AYDEMİR, Serik JAKAYEV düşey deprem etkisinden hasar gördüklerini tesbit etmişlerdir. Tasarım hesaplarında düşey yer hareketinin ihmal edilmesi, talebin ciddi şekilde hafife alınmasına, kapasitenin fazla tahmin edilmesine ve dolayısıyla genel yapısal güvenliği tehlikeye atabilir. Bu nedenle, aktif fay hatlarının yakınında, yapıların kapasite ve talebinin değerlendirilmesinde düșey zemin hareketi dikkate alınmalıdır (Kim ve Elnashai, 2008).

\section{MODELIN TASARLANMASI}

Model, betonarme kare ve dikdörtgen kesitli kolon ve kirişlerden oluşan çerçeveli simetrik yapıya sahip her yönde 6 metre aralıkta 4 açıklıklı, kat yüksekliği 3 metre olarak tasarlanan 5 katlı bir okul binasıdır (Şekil 2).

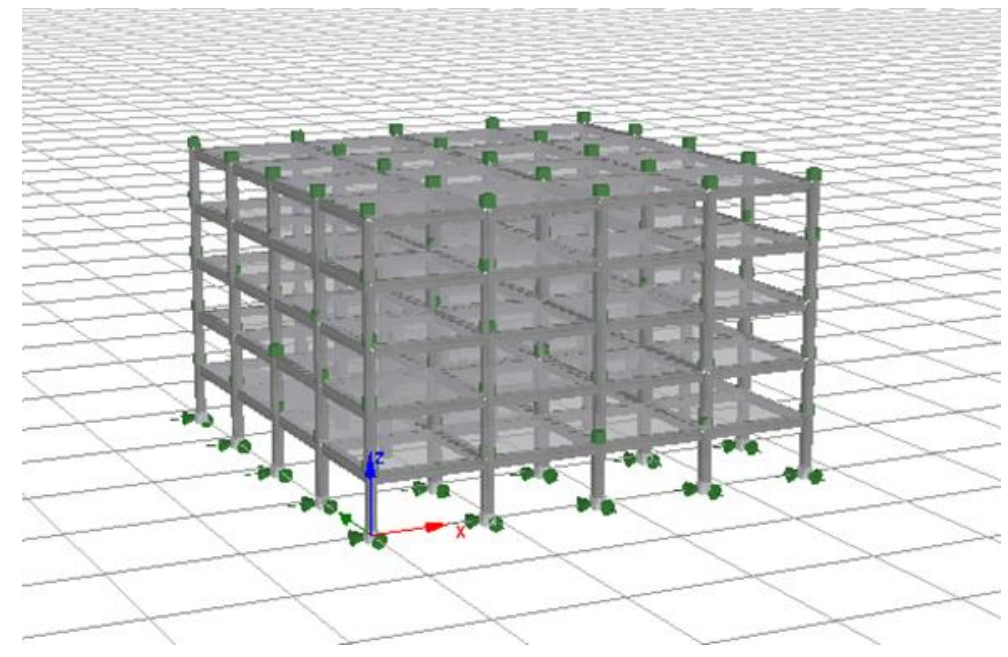

Şekil 2. Düzenli 5 katlı betonarme yapı

Çalışmada kullanılan beș katlı betonarme yapı modelinin tasarım deprem bölgesi 1 . Bölge ve zemin sınıfi Z3 olarak kabul olunduğundan bina temeli radye temel olarak seçilmiştir.

Analiz yapmak için hazırlanmış olan yapı - dizayn standardı TS500'e (URL 1) göre, deprem standardı ise TDY DBYBHY'ye (URL 2) göre tasarlanmıştır.

\subsection{Malzeme Bilgisi}

Çalışmada kullanılan bina betonarme malzemeleri TS500 ve DBYBHY-2007'ye göre seçilmişlerdir. Deprem bölgelerinde yapılacak binaların yönetmeliğine (URL 2) göre betonarme yapılarda beton sınıfı C20'den küçük kullanılamaz. Bu kurala uyarak binada kullanılan beton malzemesinin sınıfı C30 olarak seçilmiştir.

Yapıda kullanılacak çelik malzemesi sınıfı da yukarıda bahsedilen standartlara uyarak S420 olarak seçilmiştir.

\subsection{Sta4CAD Bilgisayar Programı Yardımıyla Yapı Elemanlarının Donatı Hesaplanması}

Şekil 2'de verildiği gibi yapıdaki kolonlar kesit özelliklerine bağlı olarak köşe, iç ve kenar kolonlar olarak 3 tipe ayrılmıştır. Köşe kolonlar enkesit ölçüleri 45x45 cm, iç kolonlar 55x55 cm ve kenar kolonlar ise $50 \times 50 \mathrm{~cm}$ olarak seçilmişler. Kullanılmış boyuna donatılarına göre de 2 tip kolon bulunmaktadır. Köşe kolonlarda çapı $18 \mathrm{~mm} 16$ tane donatı kullanırken, iç ve kenar kolonlarda ise çapı 18 mm 20 adet donatı kullanılmıştır. Her katta kolon enkesit alanı ve donatı miktarı eşittir. 
Düzenli Bir Betonarme Binada Düșey Deprem Bileșeninin Yapısal Davranıșa Etkisi

Kolonların donatı hesabı çözümünde kullanılan "Sta4CAD” programı her kat için, hatta her bir kolon için farklı donatı miktarlarını sonuç olarak göstermiştir. Ama çalışmada daha sonra pratik ilerlemek amacıyla donatı tipleri ve kolon enkesit alanları Şekil 2'de gösterildiği gibi kabul edilmiştir.

Şekil 3'de verildiği gibi yapıdaki kirişlerin kesit ölçüleri her katta eşit olarak 55x25 cm olarak seçilmiştir. Köşe kolonlar enkesit ölçüleri 45x45 cm, iç kolonlar 55x55 cm ve kenar kolonlar ise $50 \times 50 \mathrm{~cm}$ olarak seçilmişler. Kullanılmış boyuna donatılarına göre de 2 tip kolon bulunmaktadır. Köşe kolonlarda çapı 18 mm 16 tane donatı kullanırken, iç ve kenar kolonlarda ise çapı 18 mm 20 adet donatı kullanılmıştır. Her katta kolon enkesit alanı ve donatı miktarı eşittir.

Kolonların donatı hesabı çözümünde kullanılan "Sta4CAD" programı her kat için, hatta herbir kolon için farklı donatı miktarlarını sonuç olarak göstermiştir. Çalışmada, daha sonra pratik ilerlemek amacıyla donatı tipleri ve kolon enkesit alanları Şekil'2 de gösterildiği gibi kabul edilmiştir.

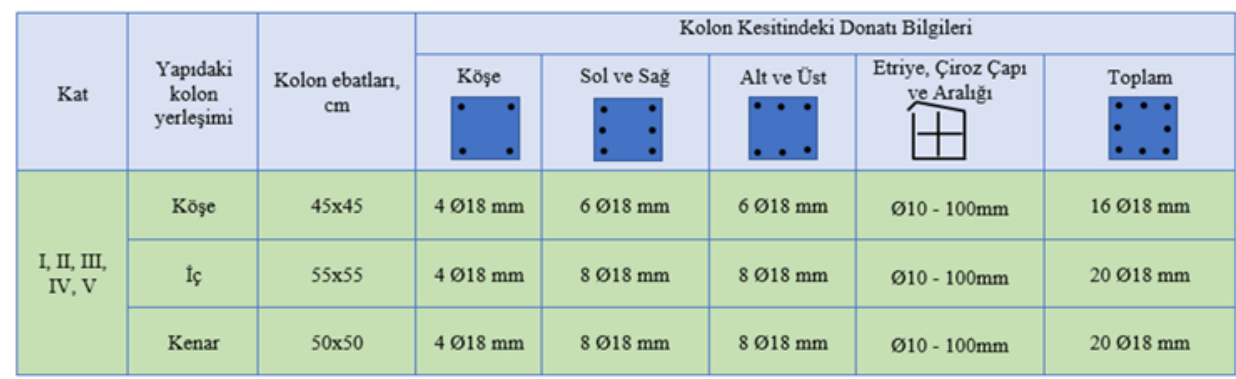

Şekil 2. Kolon boyutları ve donatı bilgileri

\begin{tabular}{|c|c|c|c|c|}
\hline \multirow{2}{*}{$\begin{array}{l}\text { Kiriş Ebath, } \\
\mathrm{cm}\end{array}$} & \multicolumn{4}{|c|}{ Kiris Donatı Bilgisi } \\
\hline & \multicolumn{3}{|c|}{ Sol Mesnet Bölgesi } & $\begin{array}{l}\text { Etriye Kalınliğ ve Ara } \\
\text { Mesafesi }\end{array}$ \\
\hline \multirow{8}{*}{$55 \times 25$} & Ust Donatı & Alt Donatı & Yan Donatı & \multirow{2}{*}{$\oslash 8-100 \mathrm{~mm}$} \\
\hline & 5018 & 3018 & 2014 & \\
\hline & \multicolumn{3}{|c|}{ Açlkluk Bōlgesi } & \multirow{3}{*}{$08-200 \mathrm{~mm}$} \\
\hline & Üst Donath & Alt Donatn & Yan Donath & \\
\hline & 5018 & $3 \emptyset 18$ & 2014 & \\
\hline & \multicolumn{3}{|c|}{ Sağ Mesnet Bölgesi } & \multirow{3}{*}{$08-100 \mathrm{~mm}$} \\
\hline & Ûst Donatı & Alt Donatn & Yan Donatn & \\
\hline & $5 \varnothing 18$ & $3 \varnothing 18$ & 2014 & \\
\hline
\end{tabular}

Şekil 3. Kiriş boyutu ve donatı bilgileri

\section{3. ÇALIŞMADA KULLANILAN HESAP YÖNTEMİ VE DEPREM KAYITLARI}

Çalışmada “Zaman Tanım Alanında Doğrusal Elastik Olmayan Yöntem” kullanılmıştır. Zaman tanım alanında doğrusal olmayan hesap esnasında ele alınan numerik model çözümü adım adım yapılacaktır (Güngör, 2010). Yapı davranışında genel olarak malzemenin katkısı çok büyüktür ve malzemenin doğrusal olmayan özelliğinin yapı elemanları kesitlerine, sonra da taşıyıcı sisteme etkisi her bir zaman tanımında tekrar yükleme yapılarak yeniden hesaplanacaktır. Yani binaya yükler eklendiği zaman gerçek yapı etkilerine yakın etkiler oluşturarak yapı davranışını öğrenmeye yol açar. Bu sebeple, malzemelerin doğrusal ve doğrusal olmayan özelliklerinin ilk olarak belirlenmesi lazımdır. Özellikleri doğrusal olmayan malzemeler kullanıldığında yapı elemanlarına dış yüklemeler tekrar tekrar verildiğinden malzeme iç kuvvetleri de artarak doğrusal-elastik durumunu geçerek doğrusal olmayan plastik davranışı gösterebilmektedir 
Afet ve Risk Dergisi Cilt: 2 Sayı: 1, 2019 (1-13)

Müberra Eser AYDEMİ, Serik JAKAYEV (Celep, 2007), o nedenle Zaman Tanım Alanında Doğrusal Olmayan Hesap (ZTADOH) yöntemi seçilmiştir, analitik çalışmada sistem hesabını çözmek için "Seismostruct" programı kullanılmıştır.

Tablo 1'de deprem kayıtları hakkında kısa bilgiler verilmiştir (URL 3). Tabloda H1 ve H2 - yatay deprem bileşeni en büyük yer ivmesini (PGA); V - düşey deprem bileşeni en büyük yer ivmesini (PGA) tanımlamaktadır.

Tablo 1. Seçilmiș deprem kayıtları

\begin{tabular}{|c|c|c|c|c|c|c|c|}
\hline \multirow{2}{*}{$\mathbf{S} / \mathbf{N}$} & \multirow{2}{*}{$\begin{array}{c}\text { Deprem Adı } \\
\text { Ve Tarihi }\end{array}$} & \multirow{2}{*}{$\begin{array}{c}\text { Kayıt } \\
\text { Alınan } \\
\text { İstasyon }\end{array}$} & \multirow{2}{*}{ Büyüklük } & \multicolumn{3}{|c|}{ En Büyük Yer İvmesi } & \multirow{2}{*}{$\begin{array}{c}\text { V/H- } \\
\text { SR }\end{array}$} \\
\hline & & & & H1(g) & $\mathrm{H} 2$ (g) & $V(g)$ & \\
\hline 1 & $\begin{array}{l}\text { Kobe, } \\
\text { Japonya } \\
01.16 .1995\end{array}$ & Takarazuka & 6.9 & 0.69 & 0.61 & 0.42 & 0.65 \\
\hline 2 & $\begin{array}{l}\text { Düzce, } \\
\text { Türkiye } \\
11.12 .1999\end{array}$ & Düzce & 7.14 & 0.4 & 0.5 & 0.34 & 0.73 \\
\hline 3 & $\begin{array}{l}\text { Northridge, } \\
\text { ABD } \\
01.17 .1994\end{array}$ & $\begin{array}{l}\text { Sylmar- } \\
\text { Converter } \\
\text { Sta }\end{array}$ & 6.7 & 0.62 & 0.92 & 0.6 & 0.77 \\
\hline 4 & $\begin{array}{l}\text { Manjil- } \\
\text { Rudbar, İran } \\
06.20 .1990\end{array}$ & Abbar & 7.37 & 0.51 & 0.49 & 0.53 & 1.07 \\
\hline 5 & $\begin{array}{l}\text { Loma Prieta, } \\
\text { ABD } \\
10.18 .1989\end{array}$ & LGPC & 6.93 & 0.57 & 0.6 & 0.89 & 1.51 \\
\hline 6 & $\begin{array}{l}\text { İmperial } \\
\text { Valley, ABD } \\
10.15 .1979\end{array}$ & Agrarias & 6.53 & 0.28 & 0.19 & 0.47 & 2 \\
\hline 7 & $\begin{array}{l}\text { İmperial } \\
\text { Valley, ABD } \\
10.15 .1979\end{array}$ & $\begin{array}{l}\text { El Centro } \\
\text { Array \#6 }\end{array}$ & 6.53 & 0.44 & 0.44 & 1.89 & 4.3 \\
\hline
\end{tabular}

\section{YATAY VE DÜŞEY DEPREM BILLEŞENLERINIIN YAPIYA ETKISİ}

Tasarlanmış olan 5 katlı betonarme bina modeline öncelikle depremin yalnızca yatay bileșenleri eklenmiş olup, daha sonra aynı modele yatay bileșenlerle birlikte düşey bileșenler de eklenmiștir. Analiz sonuçlarında, 7 deprem kaydının yatay ve düşey bileșenlerinin etkileri karşılaştırmalı olarak incelenmiştir.

\subsection{Deprem Kayıtlarının Kolonlardaki Etkisi}

Sonuçları incelenecek kolonlar, 5 katlı binanın en alt katından köşe, orta ve merkez kolonlar olacak şekilde seçilmiştir (Şekil 4). Bu şekilde farklı kolonların seçilme nedeni, yapının farklı bölgelerindeki düşey kuvvetin katılmasıyla normal kuvvetin değişimini incelemektir. Analiz sonrasında değerleri incelenecek elemanların yapının birinci katından seçilme sebebi de özel durumlar dışında her zaman birinci kat kolonlarının diğer katlardan daha fazla zorlanmasıdır. Analiz sonuçlarında hemen hemen benzer sonuçlar olduğu için yedi tane deprem kayıt sonucunun üç tanesi șekil olarak verilmiştir, diğer deprem kayıt analiz sonuçları Tablo 2'de verilmiştir. 


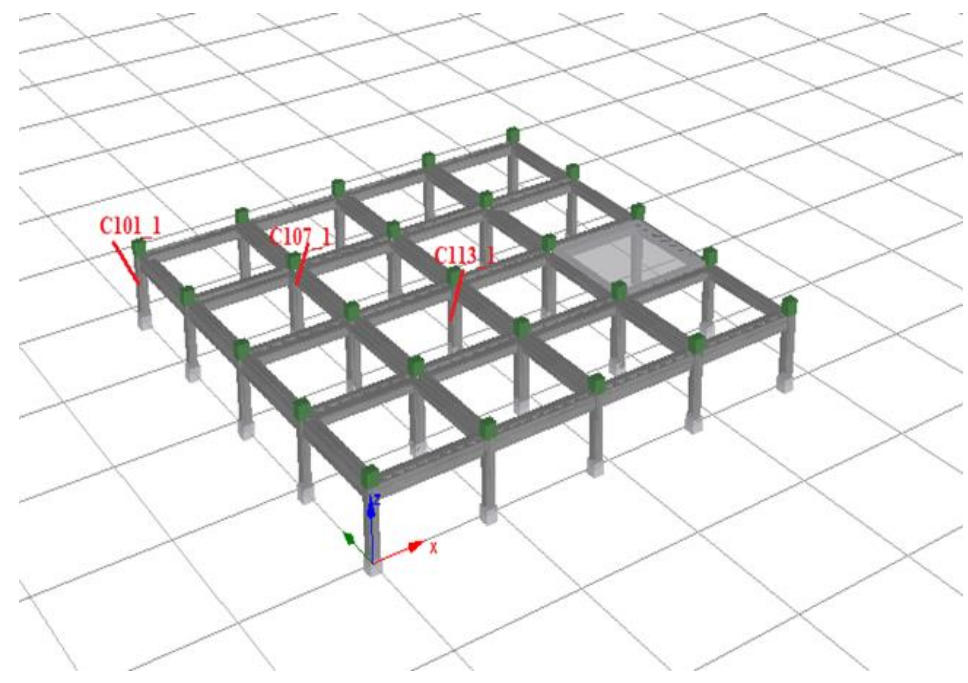

Şekil 4. Seçilmiş kolonlar

\subsubsection{Kobe Depreminin Yatay ve Düşey Bileşenlerinin Kolonlardaki Normal Kuvvet Değişimine Etkisi}

Şekil 5'de en köşe, orta ve merkez kolonlara gelen normal kuvvet değerleri verilmiştir. Model ilk önce depremin yatay $(\mathrm{X}+\mathrm{Y})$ bileşenlerine maruz kalmıştır ve sonrada depremin düşey bileşeni de hesaba katılmıştır. Dinamik analiz (Dynamic time-history analysis) sonrasında elde edilen değerler örneğin -1480 kN yatay etkiden gelen değer mor renkle ve -1607 kN yatay artı düşey etkisinden gelen kuvvet kırmızı renkle gösterilmiştir. C101_1 köşe kolon analiz sonrasında ilk önce depremin sıfır saniyesinde kolona gelen normal kuvvet - $490 \mathrm{kN}$ olarak görülmüştür ve yatay etki sonucunda $-1480 \mathrm{kN}$ değeriyle yüzde 202 artmıştır, sonra da düşey deprem etkisinin katılmasıyla bu sayı -1607 kN değeriyle yüzde 227 artışı göstererek düşey deprem etkisi eklenme sonucunda köșe kolondaki normal kuvvette yüzde 25 artış gözlemlenmiştir. C107_1 orta kolonda ise deprem başlamadan önce kolondaki maksimum normal kuvvet değeri $-1542 \mathrm{kN}$ iken yatay deprem etkisinden sonra maksimum normal kuvvet değeri -1766 KN değerle yüzde 14,5 artış ve yatay artı düşey etki sonrası normal kuvvet değeri - $2195 \mathrm{KN}$ değeriyle yüzde 42 artış kaydedilerek deprem düşey etkisi eklenmesiyle kolondaki normal kuvvet değeri yaklaşılk yüzde 27 artış göstermiştir.

C113_1 bina merkez kolonunda normal kuvvet değeri deprem öncesi -1570 kN gösterirken, deprem yatay etkisi sonrasında bu değeri $-1743 \mathrm{kN}$ göstererek yüzde 11 artış, yatay artı düşey etkisi sonrasında $-2214 \mathrm{kN}$ değeriyle yaklaşık yüzde 41 artışı göstererek düşey deprem etkisi eklenmesiyle kolondaki normal kuvvet değeri yaklaşık yüzde 30 artışa sahip olmuştur.

\subsubsection{Northridge Depreminin Yatay ve Düşey Bileşenlerinin Kolonlardaki Normal Kuvvet Değişimine Etkisi}

Grafik 6'da gözüktügü gibi Northridge depreminde de köşe kolonlarında ciddi anlamda normal kuvvet değişimi kaydedilmemiş olsa bile, orta ve merkez kolonlarda düşey kuvvetin eklenmesiyle yaklaşık yüzde 35 artış izlenmektedir. 


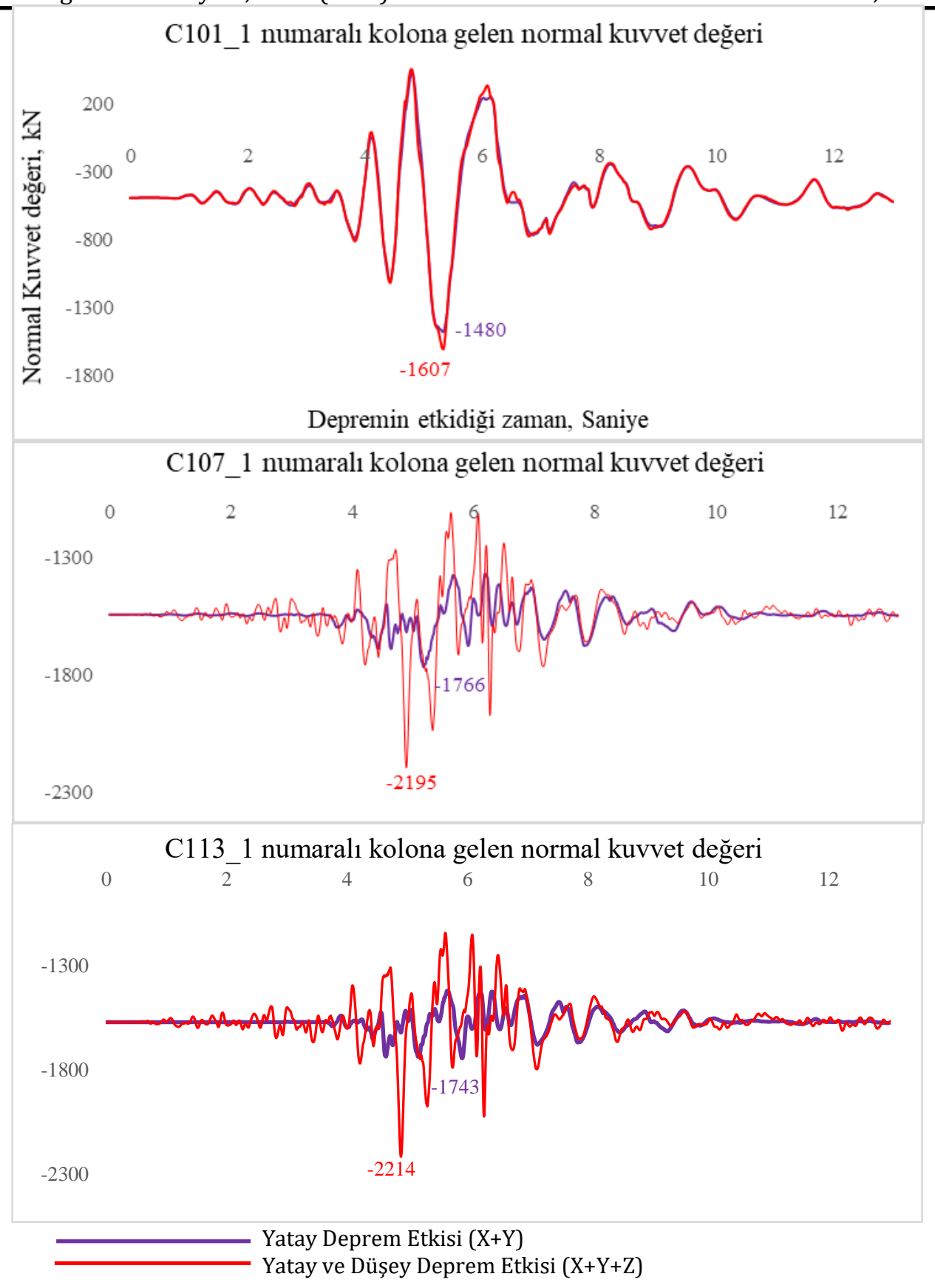

Şekil 5. Kobe depreminin sirasıyla C101_1, C107_1 ve C113_1 numaralı kolonlara gelen normal kuvvet etkisi değerleri

\subsection{3 İmperial Valley (El Centro Array \#6) Depreminin Yatay ve Düşey Bileșenlerinin Kolonlardaki Normal Kuvvet Değişimine Etkisi}

İmperial Valley depreminin yapıya yatay deprem bileșenleri ile beraber düșey deprem etkileri de eklendiği zaman merkez kolon normal yük değeri yüzde 150 olarak ciddi miktarda arttığı Şekil 7'de gözlemlenmiştir. 


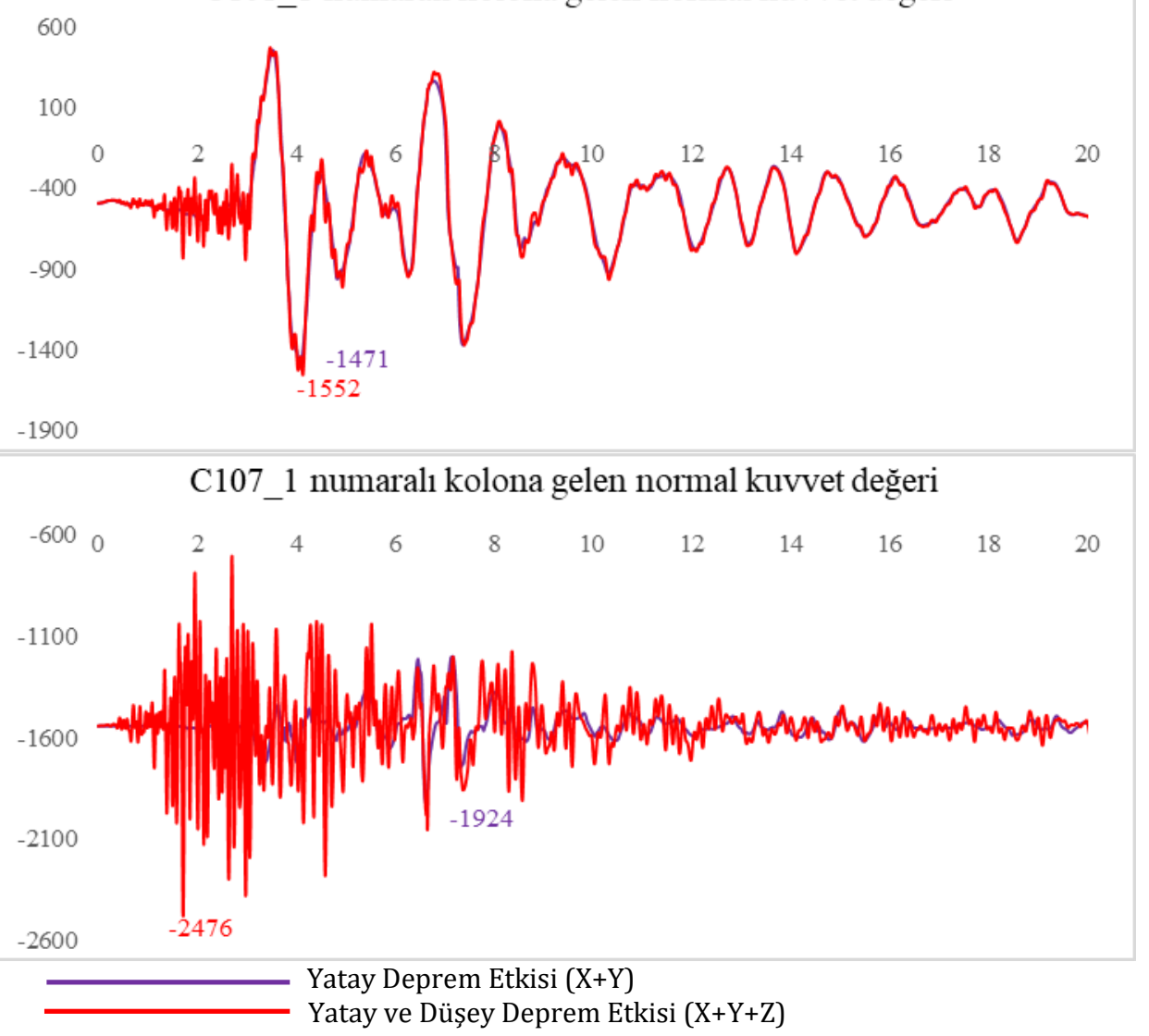

Şekil 6. Northridge depreminin sırasıyla C101_1, C107_1 ve C113_1 numaralı kolonlara gelen normal kuvvet etkisi değerleri

\subsubsection{Northridge Depreminin Yatay ve Düşey Bileșenlerinin Kolonlardaki Kesme Kuvvet Değişimine Etkisi}

Araştırmada kullanılan 7 tane deprem kayıtlarında Northridge deprem kayıtları hariç hepsinde kolonlardaki kesme kuvveti değerlerinde herhangi bir değişiklik kaydedilmemiştir (Şekil 8). Ama Northridge deprem kaydında Merkez kolondaki kesme kuvvet değeri düşey deprem bileşeninin katkısıyla yüzde 15 civarında artışa sahip olmuştur.

\subsection{Deprem Kayıtlarının Kirişlerdeki Etkisi}

Deprem sırasında yapı kirişlerine etkiyen kesme kuvveti katkısını değerlendirmek çok önemlidir. Kirişlerdeki kesme kuvveti değerlerini alabilmek için yapının 1.katından B101_1, B106_1 ve B111_1 kirişleri seçilmiştir (Şekil 9).

\subsubsection{Kobe Depreminin Yatay ve Düş̧ey Bileşenlerinin Kirişlerdeki Kesme Kuvvet Değişimine Etkisi}

Araştırmada kullanılan yedi tane deprem kayıtlarının hepsinde kirişlerdeki kesme kuvveti değerleri depremin düşey bileşeninin katılımıyla değişiklik göstermemiştir. Örnek olarak, Kobe depremi kayıtlarının kirişlere gösterdiği etkiler Şekil 10'da verilmiştir. 


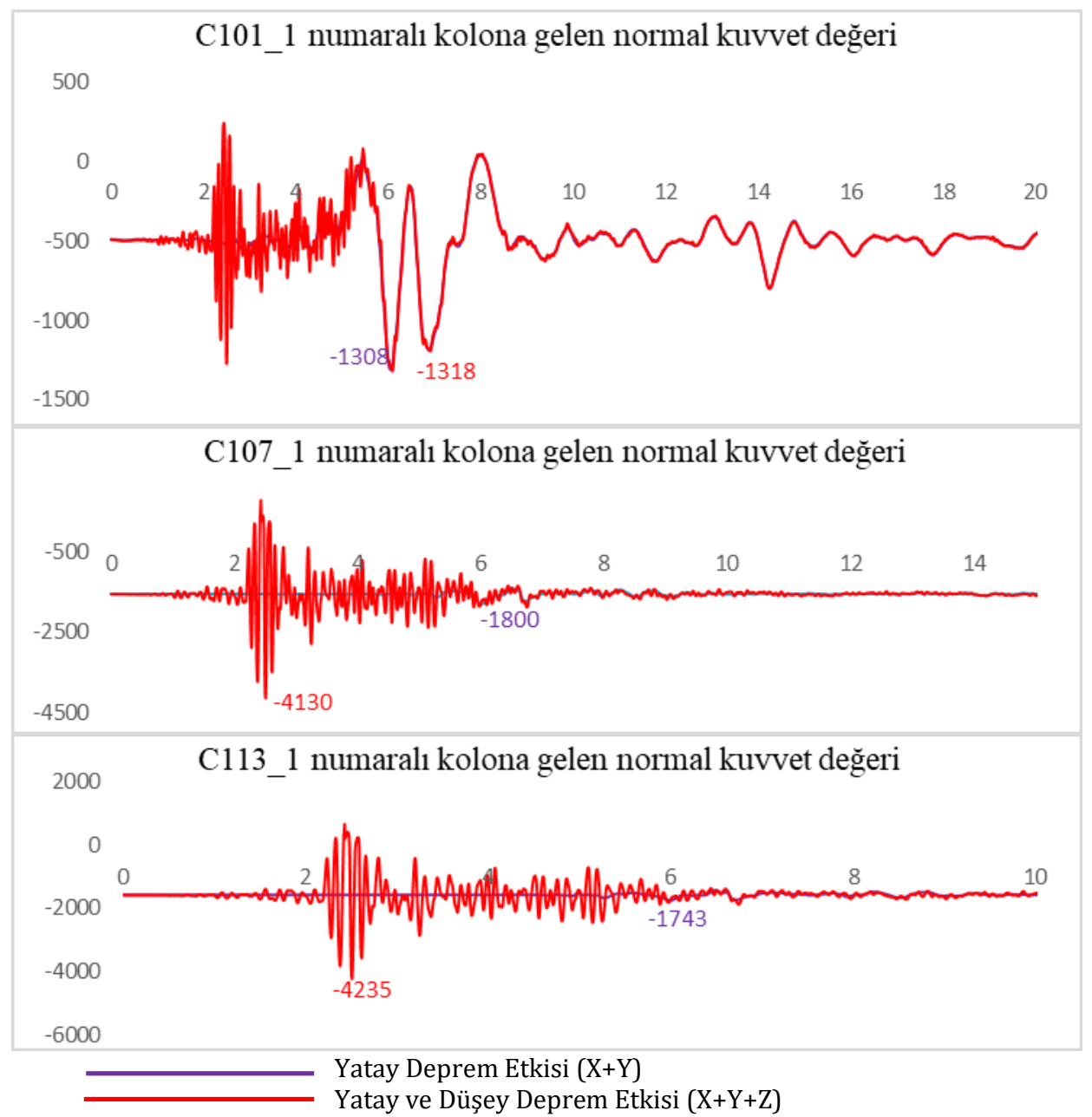

Şekil 7. İmperial Valley (El Centro Array \#6) depreminin sirasiyla C101_1,C107_1 ve C113_1 numaralı kolonlara gelen normal kuvvet etkisi değerleri

Tablo 2. Düșey deprem etkisi eklenmesi sonrası merkez kolonlardaki normal kuvvet değişimi

\begin{tabular}{|c|c|c|c|c|c|}
\hline $\mathbf{S} / \mathbf{N}$ & Deprem Adı & $\begin{array}{l}\text { Yatay } \\
\text { Deprem } \\
\text { Etkisi } \\
\text { Sonrası } \\
\text { Normal } \\
\text { Kuvvet } \\
\text { Artışı, \% }\end{array}$ & $\begin{array}{l}\text { Yatay Artı } \\
\text { Düşey } \\
\text { Deprem } \\
\text { Etkisi } \\
\text { Sonrası } \\
\text { Normal } \\
\text { Kuvvet } \\
\text { Artışı, \% }\end{array}$ & $\begin{array}{c}\text { Farklılık, } \\
\%\end{array}$ & $\begin{array}{l}\text { Düşey } \\
\text { Deprem } \\
\text { Etkisi } \\
\text { Ortalama } \\
\text { Artış, \% }\end{array}$ \\
\hline 1 & Kobe & 11 & 41 & 30 & \multirow{7}{*}{46} \\
\hline 2 & Düzce & 13 & 30 & 17 & \\
\hline 3 & Northridge & 26 & 60 & 34 & \\
\hline 4 & Manjil-Rudbar & 9 & 54 & 45 & \\
\hline 5 & Loma Prieta & 21 & 40 & 19 & \\
\hline 6 & $\begin{array}{l}\text { İmperial } \\
\text { Valley(Agrarias) }\end{array}$ & 6 & 29 & 23 & \\
\hline 7 & $\begin{array}{l}\text { İmperial Valley (El } \\
\text { Centro Array \#6) }\end{array}$ & 11 & 169 & 158 & \\
\hline
\end{tabular}




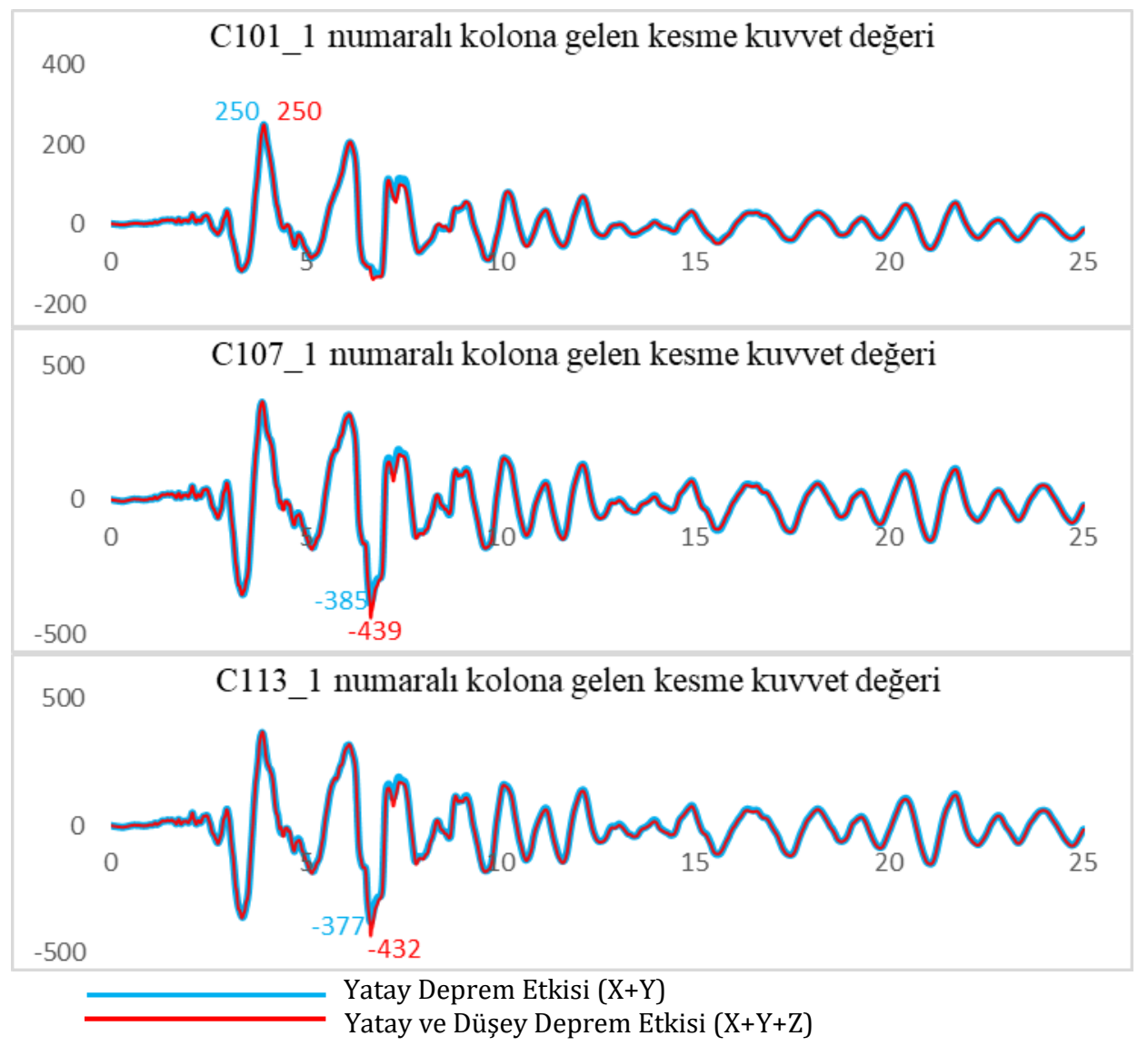

Şekil 8. Northridge depreminin sırasıyla C101-1, C107_1 ve C113_1 numaralı kolonlara gelen kesme kuvvet etkisi değerleri

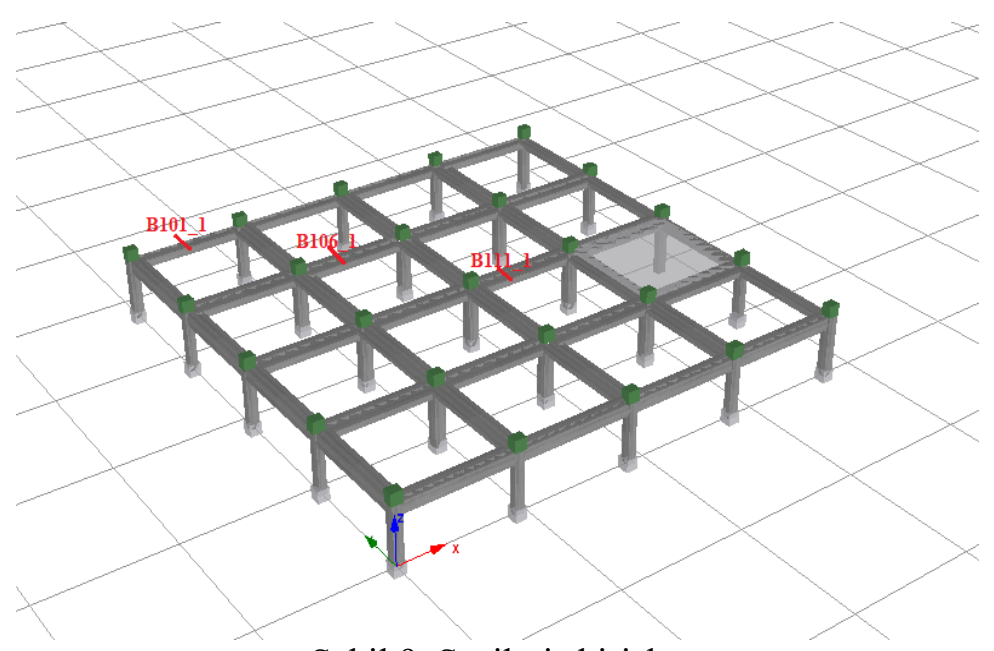

Şekil 9. Seçilmiş kirişler 


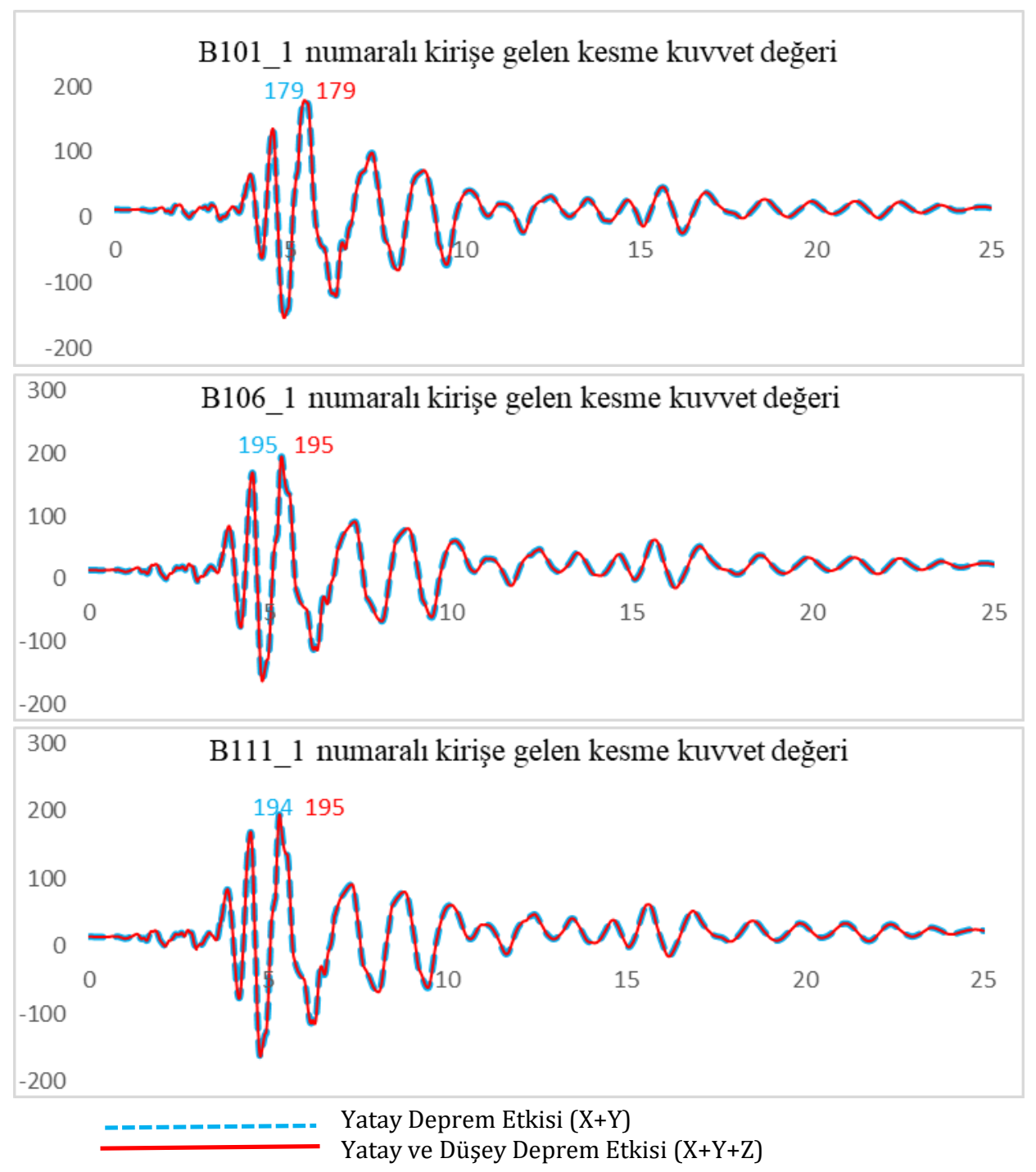

Şekil 10. Kobe depreminin sırasıyla B101_1, B106_1 ve B111_1 numaralı kirişlere gelen kesme kuvvet etkisi değerleri

\section{SONUÇ}

Araştırmada depremin düşey bileşeninin yapısal davranışa etkisinin incelenmesi amacıyla analitik bir çalışma yapılmıştır. Bu amaçla simetrik ve düzenli bir plana sahip beş katlı bir betonarme okul binası ele alınmıştır. Seismostruct programı ile yedi deprem kaydı kullanılarak, yatay bileşenlerin eklendiği durum ile yatay ve düşey bileşenlerin birlikte eklendiği durumlar için zaman tanım alanında analizler yapılarak sonuçlar karşılaştırılmıştır. Buna göre, yapıya deprem kayıtlarının yatay bileşenlerinin yanı sıra düşey bileşeninin de eklenmesi durumunda yapı kolonlarındaki, özellikle orta kolonlardaki normal kuvvetler göz ardı edilemeyecek düzeyde artış göstermiştir. Buna karşın kolonlardaki kesme kuvvetleri düzeyinde önemli bir artış gözlenmemiş olmakla birlikte, kullanılan deprem kayıtlarından birinde yüzde on beş oranında bir artış gözlenmiştir. Benzer şekilde yapıdaki kiriş kesme kuvvetlerinde herhangi bir değişiklik kaydedilmemiştir.

Düşey deprem etkisinin, kat ötelemeleri ve yapısal deplasmanlar üzerinde de önemli bir etkisi gözlenmemiştir. Bununla birlikte, yatay deprem bileşenlerinin yanı sıra düşey deprem bileşeninin de eklenmesi durumunda kat deplasmanlarında küçük oranda azalma meydana geldiği görülmüştür. 
Düzenli Bir Betonarme Binada Düșey Deprem Bileșeninin Yapısal Davranıșa Etkisi

Kolonlardaki normal kuvvet düzeyi, deprem kayıtlarının yatay bileşenlerinin yanı sıra düşey bileşeninin de eklenmesi durumunda kolonların binalardaki konumlarına göre değişmektedir. Örnek olarak, bir deprem kaydı için, binanın köşe kolonlarındaki normal yük düzeyinde bir farklılık gözlenmezken, kenar ve orta kolonlardaki normal yük düzeyinde belirgin değişiklikler gözlenmiştir.

Bu çalışmada göz önüne alınan yapısal sistemin tek çeşit olması ve kullanılan deprem kaydı sayısının az olması sebebiyle, yapılan analitik çalışmalardan kapsamlı bir öneride bulunmak oldukça güçtür. Ancak düşey deprem etkisinin kolonlarda normal kuvvetlerini arttırdığı, diğer bazı çalışmalarda da gözlenmiş olup, bu noktadan hareketle, özellikle yeni yapılacak yapıların tasarımında depremin düş̧ey bileşeninin de dikkate alınmasının gerekli olduğu söylenebilir. Gelecekteki çalışmalarda, farklı kat sayısı ile özellikle planda ve düşeyde düzensizliğe sahip binalarda, depremin düşey bileşeninin yapısal davranışa etkisinin araştırılması önemlidir.

\section{KAYNAKLAR}

Abrahamson N. A. and Litehiser J. J., (1989). “Attenuation of vertical peak acceleration”, Bull. seism. soc. Am. 79.

Ambraseys, N. N. and Douglas, J., (2003). "Effect of vertical ground motions on horizontal response of structures". International Journal of Structural Stability and Dynamics.

Bozorgnia Y., (2014). "Vertical ground motion", Pacific earthquake engineering research center's presentation.

Bozorgnia Y., Niazi M. and Campbell K. W. (1995). "Characteristics of free-field vertical ground motion during the Northridge earthquake", Earthquake Spectra 23.

Celep, Z. (2007). Betonarme sistemlerde doğrusal olmayan davranıș: plastik mafsal kabulü ve çözümleme. Altıncı Ulusal Deprem Mühendisliği Konferansı, 16-20.

Chopra A.K. (1966). The importance of the vertical component of earthquake motions. Bulletin of the Seismological Society of America, V. 56, No. 5.

Ehsan Noroozinejad Farsangi and Abbas Ali Tasmini, (2016), "The influence of coupled horizontal-vertical ground excitations on the collapse margins of modern RC-MRFs”. Int J Adv Struct Eng (2016).

Güngör 0., (2010). "Mevcut bir karayolu köprüsünün doğrusal ve doğrusal olmayan yöntemler ile Performans değerlendirmesi”. Yüksek Lisans Tezi. İstanbul teknik Üniversitesi.

Kim, S. J., \& Elnashai, A. S. (2008). Seismic assessment of RC structures considering vertical ground motion. Mid-America Earthquake Center CD Release 08-03.

Kim, S. J., Holub, C. J., \& Elnashai, A. S. (2010). Analytical assessment of the effect of vertical earthquake motion on RC bridge piers. Journal of Structural Engineering, 137(2), 252-260.

Koukleri S. N., "The effect of vertical ground excitation on the response of RC structures”, MSc. Dissertation, Imperial College, August 1992.

Newmark, N. M., Hall, W. J., \& Mohraz, B. (1973). A study of vertical and horizontal earthquake spectra. Report WASH-1255, Directorate of Licensing, US Atomic Energy Commission.

Papaleontiou C. and Roesset J. M., "Effect of vertical accelerations on seismic response of frames", in T. Moan et al., (eds) Structural Dynamics-EURODYN’Y3, Balkema, Rotterdam, 1993, pp. 19-26. 
Afet ve Risk Dergisi Cilt: 2 Sayı: 1, 2019 (1-13)

Papazoglou' A. J. and Elnashai A. S., (1996). "Analytical and field evidence of the damaging effect of vertical earthquake ground motion". Earthquake engineering and structural dynamics, Vol. 25.

URL 1, "TS500", Betonarme yapıların tasarım ve yapım kuralları.

http://www.resmigazete.gov.tr/eskiler/2000/07/20000712M1-23.pdf (Son Erişim: 02.11.2018)

URL 2, "DBYBHY-2007", Deprem bölgelerinde yapılacak binalar hakkında esaslar. http://www.resmigazete.gov.tr/eskiler/2007/03/20070306-3.htm (Son Erişim: 02.11.2018)

URL 3, "PEER Ground Motion Database, NGA-West2" internet sitesinden ulaşlabilir https://ngawest2.berkeley.edu (Son Erişim: 02.11.2018)

Weichert, D.H., Wetmiller, R.J. and Munro, P. (1986). “Vertical Earthquake Acceleration Exceeding 2 g? The Case of the Missing Peak", Bulletin of the Seismological Society of America, Vol. 76, No. 5. 